\title{
Floral asymmetry and predation risk modify pollinator behavior, but only predation risk decreases plant fitness
}

\author{
Pablo Augusto Poleto Antiqueira ${ }^{1,3} \cdot$ Gustavo Quevedo Romero $^{2}$
}

Received: 28 May 2015 / Accepted: 15 January 2016 / Published online: 10 February 2016

(C) Springer-Verlag Berlin Heidelberg 2016

\begin{abstract}
Although predators and floral herbivores can potentially decrease plant fitness by changing pollinator behaviors, studies comparing the strength of these factors as well as their additive and interactive effects on pollinator visitation and plant fitness have not been conducted. In this study, we manipulated the floral symmetry and predator presence (artificial crab spiders) on the flowers of the shrub Rubus rosifolius (Rosaceae) in a $2 \times 2$ factorial randomized block design. We found that asymmetry and predators decreased pollinator visitation (mainly hymenopterans), and overall these factors did not interact (additive effects). The effect of predation risk on pollinator avoidance behavior was $62 \%$ higher than that of floral asymmetry. Furthermore, path analyses revealed that only predation risk cascaded down to plant fitness, and it significantly decreased fruit biomass by $33 \%$ and seed number by $28 \%$. We also demonstrated that $R$. rosifolius fitness is indirectly affected by visiting and avoidance behaviors of pollinators.
\end{abstract}

Communicated by Carlos L. Ballare.

Electronic supplementary material The online version of this article (doi:10.1007/s00442-016-3564-y) contains supplementary material, which is available to authorized users.

Gustavo Quevedo Romero

gqromero@gmail.com

1 Programa de Pós-Graduação em Biologia Animal, IBILCE, Universidade Estadual Paulista (UNESP), São José do Rio Preto, Brazil

2 Departamento de Biologia Animal, Instituto de Biologia (IB), Universidade Estadual de Campinas (UNICAMP), Campinas, Brazil

3 Present Address: Programa de Pós-Graduação em Ecologia, Instituto de Biologia (IB), Universidade Estadual de Campinas (UNICAMP), Campinas, Brazil
The strong avoidance behavioral response triggered by predation risk may be related to predator pressure upon flowers. Although floral asymmetry caused by herbivory can alter the quality of resources, it should not exert the same evolutionary pressure as that of predator-prey interactions. Our study highlights the importance of considering simultaneous forces, such as predation risk and floral asymmetry, as well as pollinator behavior when evaluating ecological processes involving mutualistic plant-pollinator systems.

Keywords Trait-mediated indirect interaction .

Mutualism · Plant reproductive success · Flowering plant evolution $\cdot$ Path analysis

\section{Introduction}

Flowering plant evolution is directly linked to pollinatorplant relationships and is represented by adaptations to attract pollinators, transport greater amounts of pollen and increase fecundity (Lloyd and Barret 2006; Schiestl and Johnson 2013). Unsuccessful pollination caused by transported pollen of low quantity or quality can greatly reduce the reproductive success of plants. Therefore, factors that contribute to pollen limitations can have a great impact on plant fitness and may decrease visitation by pollinators that act as pollen vectors (Ashman et al. 2004; Knight et al. 2005a). The plant-pollinator system is only one level of a web of interactions mediated by plants that can be affected by other levels of the trophic web, such as herbivores and predators (Ohgushi et al. 2007; Ings et al. 2009). The effect of these interactions can occur directly via plant damage or indirectly via interrupted connections between pollinators and plants. Although the consequences of indirect interactions on food web dynamics have received special attention 
over the last few years (Wootton 1994; Stocks et al. 2003; Knight et al. 2005b), it is unclear whether interactions among the indirect effects of predators and herbivores occur and change in magnitude through a trophic cascade until they impact plant fitness.

Predators can transmit indirect effects throughout the food web and cause alterations to the community's structure. These effects may result from interactions mediated by density, such as predators eating prey and lowering prey abundance (Romero and Koricheva 2011), or mediated by traits, such as predators influencing prey behavior (Schmitz 1998; Dukas and Morse 2003; Gonçalves-Souza et al. 2008; Romero et al. 2011). Insects that consume flower pollen and floral nectar are under constant risk of predation by other arthropods that use flowers as foraging sites (Robertson and Maguire 2005). These predatory arthropods include spiders of the family Thomisidae, and they usually inhabit flowers of various species of plants (Foelix 2010) and typically hunt insects by using their anterior raptorial legs (Suttle 2003; Morse 2007). Once on the flowers, these predators can directly interfere with the behavior of pollinators and indirectly decrease the plant's fitness (Suttle 2003; Dukas and Morse 2005; Gonçalves-Souza et al. 2008).

Apart from predators, flowering plants suffer from interactions with other potential antagonists, such as herbivores, pollen-stealing animals and seed predators (Karban and Baldwin 1997; Cariveau et al. 2004). Herbivory can have an important influence on plant reproduction and population growth (Louda 1983; Marquis 1984). Florivory is any damage caused by consumers to developing floral tissues or mature flowers before the formation of seed coverage (McCall and Irwin 2006). Florivores can directly decrease plant fitness by destroying primary reproductive tissues (e.g., anthers and ovaries) (Maron and Crone 2006; Wise and Cummins 2002; Althoff et al. 2005) and indirectly by damaging accessory reproductive tissues (e.g., petals and sepals) that attract pollinators (Cardel and Koptur 2010; Botto-Mahan et al. 2011). Damage to petals and sepals can alter the appearance of individual flowers and inflorescences and may prevent visits from pollinators (Karban and Strauss 1993; McCall 2008). When this effect is more intense, florivory can result in asymmetric corollas because pollinator preferences can vary in corollas with radial or bilateral symmetry (Møller 1995; Wignall et al. 2006).

Herbivory is responsible for a large proportion of plant richness and complexity of interactions in terrestrial systems (Ohgushi 2005). However, most empirical studies have focused on leaf damage, and florivory effects are relatively understudied despite studies showing that they are comparatively common in nature (McCall and Irwin 2006). In addition, although the presence of predators (i.e., crab spiders) on flowers is conspicuous, to our knowledge, limited empirical evidence is available on the role played by these predators in mutualistic relationships between pollinators and flowering plants in tropical regions (Romero and Vasconcellos-Neto 2004; Morse 2007; Gonçalves-Souza et al. 2008). Moreover, the combined effects of predation risk and floral herbivory on the behavior of pollinators and reproductive success of plants are unknown. Here, we have manipulated the effect of symmetry and risk of predation (by crab spiders) on flowers of the bush Rubus rosifolius (Rosaceae). We predict that the risk of predation and effect of floral asymmetry can negatively affect pollinator behavior and decrease plant fitness in an additive or interactive (non-additive) way. Effects of risk of predation and of floral asymmetry might not interact (additive response) and therefore might be predicted directly from the additive accumulation of impacts associated with a single factor. On the other hand, synergistic effects might emerge from interactions between factors (Piggott et al. 2015). For instance, synergistic effects between predation risk and floral asymmetry combined are expected whether or not cumulative effects of these multiple negative factors are greater than the additive sum of effects produced by the factors acting in isolation. A possible biological explanation for synergistic effects in our study system is, for example, the greater conspicuity of predators in asymmetrical flowers, improving the pollinators' capacity of recognizing predation risk. This would decrease pollinator visitation and, indirectly, the plant fitness in asymmetrical flowers with predator presence. We also predict that the magnitude of effects caused by predation risk will be stronger than that of floral asymmetry (herbivory damage) because of the greater impact of predators on the fitness of flower visitors.

\section{Materials and methods}

\section{Study area and organisms}

The present study was performed at the Biological Reserve of Serra do Japi, which is located west of the Atlantic Plateau close to the city of Jundiaí in the state of São Paulo, Brazil. The terrain is characterized by altitudes varying from approximately 700-1300 m a.s.l. (Santoro and Machado 1992), and the climate is seasonal with a yearly mean temperature varying from $15.7^{\circ} \mathrm{C}$ in the highest area to $19.2{ }^{\circ} \mathrm{C}$ in the lowest area. The coldest month is July, with mean temperatures varying from 11.8 to $15.3{ }^{\circ} \mathrm{C}$; the hottest month is January, with mean temperatures varying from 18.4 to $22{ }^{\circ} \mathrm{C}$ (http://www.jundiai.sp.gov.br). The vegetation is composed of altitude semideciduous mesophilous forest that transitions to semideciduous mesophilous forest and features a rock floor. 
The bush $R$. rosifolius (Rosaceae) is widely distributed in a variety of tropical habitats and is fairly common in the Biological Reserve of Serra do Japi. Its height can vary from 1.0 to $2.0 \mathrm{~m}$, and it has composed leafs with from five to seven membranous leaflets. The flowers are hermaphrodite, white, and their diameter varies from 1.8 to $2.0 \mathrm{~cm}$; each branch can produce from one to four flowers during the year and they are pollinated by insects, mainly Lepidoptera, Hymenoptera and Diptera (Gonçalves-Souza et al. 2008). The fruits are an important food source for a variety of frugivorous birds and mammals (e.g., Penelope sp., Cracidae). Gonçalves-Souza et al. (2008) observed the highest number of species from the Lepidoptera order visiting this species during their study period; however, Hymenoptera were the most abundant. These authors also verified that plants visited by flower-visiting insects produced higher biomass infructescences and higher seed numbers compared with plants for which insects were prevented from visiting. This result indicates that $R$. rosifolius depends on insect pollination to conclude its reproductive cycle.

\section{Effect of floral asymmetry and predation risk on flower-visiting insects and plant reproductive success}

To test the effects of floral damage (asymmetry) and predation risk on the behavior of pollinator insects and the fitness of plants, we selected and followed 112 plants growing naturally in the field and independently distributed. The plants were divided into 28 blocks, with at least 10-m distance between them, with four individuals in each block. We selected one flower from each plant and randomly applied one of the following treatments: (1) control symmetric flower without spiders; (2) symmetric flower with spiders; (3) asymmetric flower without spiders; and (4) asymmetric flower with spiders. As a predator model, we used artificial crab spiders because of their ease of handling and similar effect to real spiders on flower-visiting insect behavior (Antiqueira 2012). These spiders were placed on the petals of flowers to simulate the foraging mode of crab spiders. Details on the spider model can be found in GonçalvesSouza et al. (2008). To verify the frequency of Thomisidae spiders on naturally symmetric and asymmetric flowers of $R$. rosifolius, approximately 200 flowers were randomly inspected at the study site.

Prior to selecting the experimental flowers, the floral buds of plants were bagged with tulle fabric to prevent floral damage from herbivores as well as ovule fertilization before the beginning of the experiment. Plants were observed daily, and as soon as their flowers were completely open, measurements were performed for the floral diameter (centimeters), flowering time (no. of days in which the flower was open), leaf number and number of flowers, and the values were used as covariates in the statistical models. Each flower then received one of the symmetry treatments, with flowers considered symmetric if they showed no morphological alterations and asymmetric if they had two out of five petals removed with the help of scissors to simulate the effect of floral herbivores common to the area (P. A. P. Antiqueira, personal observations). Neighboring petals were removed to produce asymmetry, which has been suggested to reduce the number of insect visitors. To control potential effects of floral damage that did not compromise the asymmetry effect, such as the influence of possible volatiles emitted by the damaged floral tissue that can either drive off or attract insects, damage was also caused at the distal ends of petals of symmetric flowers, and the natural shape of the edge was maintained with the help of scissors to avoid affecting floral symmetry. To minimize the effect of resource availability, we selected only newly opened young flowers for the experiment. All of the flowers of each block were separated by a distance of at least $30 \mathrm{~cm}$ to minimize any effect of spiders on the visitation of insects to other control flowers (i.e., flowers without spiders). Experimental flowers were observed from a distance of at least $2 \mathrm{~m}$ to avoid the influence of the observer on the behavior of visitor insects. The flowers from each block were simultaneously observed in four sections of $40 \mathrm{~min}$ each, with 10-min intervals between sections, for a total of $160 \mathrm{~min}$ of observations per replica. During this period, the number of visits as well as the number of incidents of flower avoidance by flower-visiting insects was recorded. The term "visit" was defined as an event in which the insect landed on the flower or remained on it for at least $2 \mathrm{~s}$, and "avoidance" was defined as an event when the insect flew towards the flower but dodged and approached another nearby flower without landing.

To test the effects of floral asymmetry (simulating florivory) and predation risk on plant fitness, the same plants from the flower-visiting behavior assessment experiment were used. After floral senescence (withered stigma), the spiders were removed and flowers were then bagged again with tulle fabric to avoid consumption by frugivores (e.g., Penelope sp.). After fruit ripening, they were collected, stored separately and weighted on a $10^{-4}-\mathrm{g}$ precision scale. The number of seeds was counted with the help of a magnifier.

\section{Statistical analyses}

The experimental design was randomized blocks. Visitation, insect avoidance (total, Hymenoptera, Lepidoptera+Diptera), infructescence biomass (g) and seed number per infructescence were the response variables. We used the lme function in the nlme package 
(Pinheiro and Bates 2000; Pinheiro et al. 2015), and dredge and model.avg functions in the MuMIn R library (Barton 2015) to assess models and estimate parameter values. In these models, predation risk, floral asymmetry and interaction between these factors were the predictor variables, and block was a random factor. We included diameter of floral receptacle, flowering time in days (no. of days in which the flower was open), number of leaves and number of flowers per plant as covariates. We ran a complete set of models with all possible combinations of the fixed effects and to identify the set of best models according to the criterion of $\Delta$ Akaike information criterion (AICc) $<2$ (Burnham and Anderson 2002). We then performed model averaging to estimate coefficients and the relative importance of the predictor variables, calculated as the sum of the Akaike weights of all the models in which a particular predictor appears (Burnham and Anderson 2002) for each subset of indices. There is a well-known difficulty in comparing the coefficient of determination in linear mixed models (LMM), as there is in general linear models (Zuur et al. 2009). Following the approach of other studies (Patiño et al. 2013; Santos et al. 2015) we used a $R^{2}$ measure that compares the deviance of the LMM with the deviance of a linear intercept-only model $\left[R^{2}=1-\Sigma(y-\hat{y})^{2} /\right.$ $\Sigma(y-\bar{y})^{2}$ (Kvalseth 1985)]. We then used these $R^{2}$-values as indicators of the proportion of the total variation among response variables that is explained (accounted for) by selected LMMs. These analyses were performed using the language environment $\mathrm{R}$ version 3.2.2 (R Developmental Core Team 2015; http://www.Rproject.org).

We performed path analyses to summarize the main effects of the investigated factors and to explore the magnitude and indirect effects of predation risk and floral asymmetry on the behavior of pollinators and components of plant fitness. Plant fitness (fruit biomass and number of seeds) and flower-visiting insect behavior (visitation and avoidance) were endogenous variables, and treatments (predators and floral symmetry) were exogenous variables. The models were used to test the prediction that predation risk and floral damage indirectly affect plant fitness via changes in the behavior of pollinator insects. Two models were explored, one for each fitness component of $R$. rosifolius (i.e., fruit biomass and number of seeds). Path analyses were performed using the software AMOS version 20 (SPSS, Chicago, IL).

\section{Results}

The flower visitors recorded in the experimental observations belonged to 41 morphospecies (Table S1), with the order Lepidoptera showing the greatest richness at 19 morphospecies $(46.3 \%)$, followed by Hymenoptera with 16 morphospecies (39\%) and Diptera with six morphospecies $(14.6 \%)$. However, despite having the greatest richness, the number of visits by Lepidoptera and Diptera was lower, with Hymenoptera visiting the studied plants most frequently. Therefore, Diptera and Lepidoptera were grouped for the performance of statistical analyses. We verified that crab spiders occur in symmetric and asymmetric flowers at a frequency of 5.1 and $4.7 \%$, respectively.

Both flower symmetry and predator presence were important factors in affecting visitor behavior and plant fitness (Figs. 1, 2); the interactive effects of these factors were more common for visitation than for avoidance behavior and plant fitness, and overall interactions explained very few of the total variations in all these analyses (Tables 1,2). There were $44 \%$ fewer total visits to asymmetric flowers than symmetric flowers and $40 \%$ fewer to flowers with predators than to flowers without predators. Compared with symmetric flowers, asymmetry increased the total avoidance by approximately $5 \%$; therefore, asymmetry was not considered a good predictor of variations in total avoidance by insects among the treatments (Table 1; Fig. 1b). In general, predation risk effects on pollinator avoidance behavior were $61.7 \%$ higher compared with floral asymmetry effects. Certain plant characteristics influenced the behavior of flowervisiting insects, with a greater number of flower visits with less flowering time (Table 1). The diameter of floral receptacle, however, affected visitation and insect avoidance (Table 1).

Specifically for Hymenoptera, flower symmetry and predator presence were influential (Table 1; Fig. 1a), with visitation $42 \%$ lower in asymmetric flowers than in symmetric flowers, and $28 \%$ lower in flowers with predators than in flowers without predators. With regard to avoidance behavior in this group, predation risk increased avoidance by $64 \%$ compared with flowers without predation risk (Fig. 1b; Table 1). Asymmetry, however, increased avoidance behavior by only $2 \%$ and was not considered a good predictor to explain variation in avoidance behavior among these insects between treatments (Table 1). For the Diptera+Lepidoptera group, predator presence strongly decreased visits from these insects by approximately $370 \%$ (Fig. 1a), whereas floral asymmetry only caused a decrease of $64 \%$ in visitation; however, asymmetry was not considered a good predictor in the selected model (Table 1). Similar results were observed for avoidance behavior in this group, which was not significantly affected by asymmetry (Table 1). Predation risk, however, was the predictor that best explained variation between treatments (Table 1) and increased avoidance by $40 \%$ in the Diptera+Lepidoptera group.

Asymmetry was not considered a good predictor for explaining variation in fresh infructescence biomass 
Fig. 1 Mean number of a visits and $\mathbf{b}$ avoidance/160 min of all flower-visiting insects (Total), as well as of Hymenoptera and Diptera+Lepidoptera $(n=18)$ from symmetric and asymmetric flowers (flowers with two neighboring petals removed) in the presence and absence of predators (artificial crab spider). Error bars represent $\pm \mathrm{SE}$
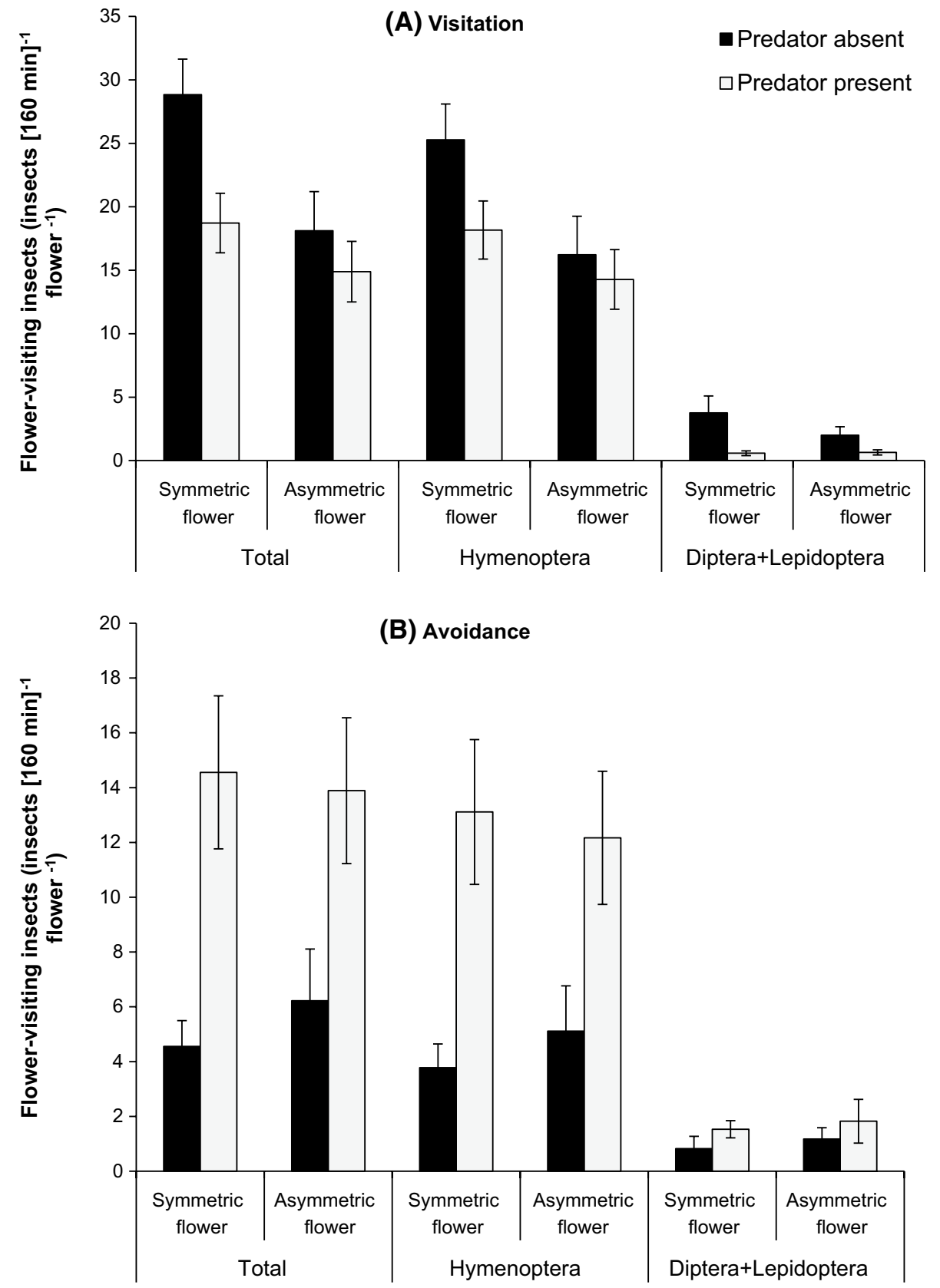

(Table 2), i.e., asymmetry decreased biomass by only $10.5 \%$ compared with symmetric flowers (Fig. 2a). Predator presence, however, decreased infructescence biomass by $33 \%$ compared with that of flowers without the presence of predators (Fig. 2a). Although the number of seeds was $14.2 \%$ higher in fruits from symmetric flowers than in fruits from asymmetric flowers, this effect was not relevant (Table 2; Fig. 2b). However, predation risk decreased the number of seeds by $28.4 \%$ (Fig. 2b), showing that predators have stronger effects on plant fitness than does florivory (Table 2).

The results from the path analyses showed that alterations in visiting and avoidance behavior of flower-visiting insects because of herbivore and predator effects can affect plant fitness components (Fig. 3; Table 3). The decrease in fruit biomass in the presence of predators was strongly mediated by avoidance behavior of pollinators (Fig. 3a), suggesting the importance of this behavior on plant reproductive success, such as on fruit quality for possible dispersers. The number of seeds, however, was similarly affected by the visiting and avoidance behavior of insects. Predator presence primarily affected avoidance, whereas asymmetry affected pollinator visitation (Fig. 3b). Therefore, $R$. rosifolius fitness is indirectly affected by alterations in visiting and avoidance behavior of pollinators in a complementary manner. 

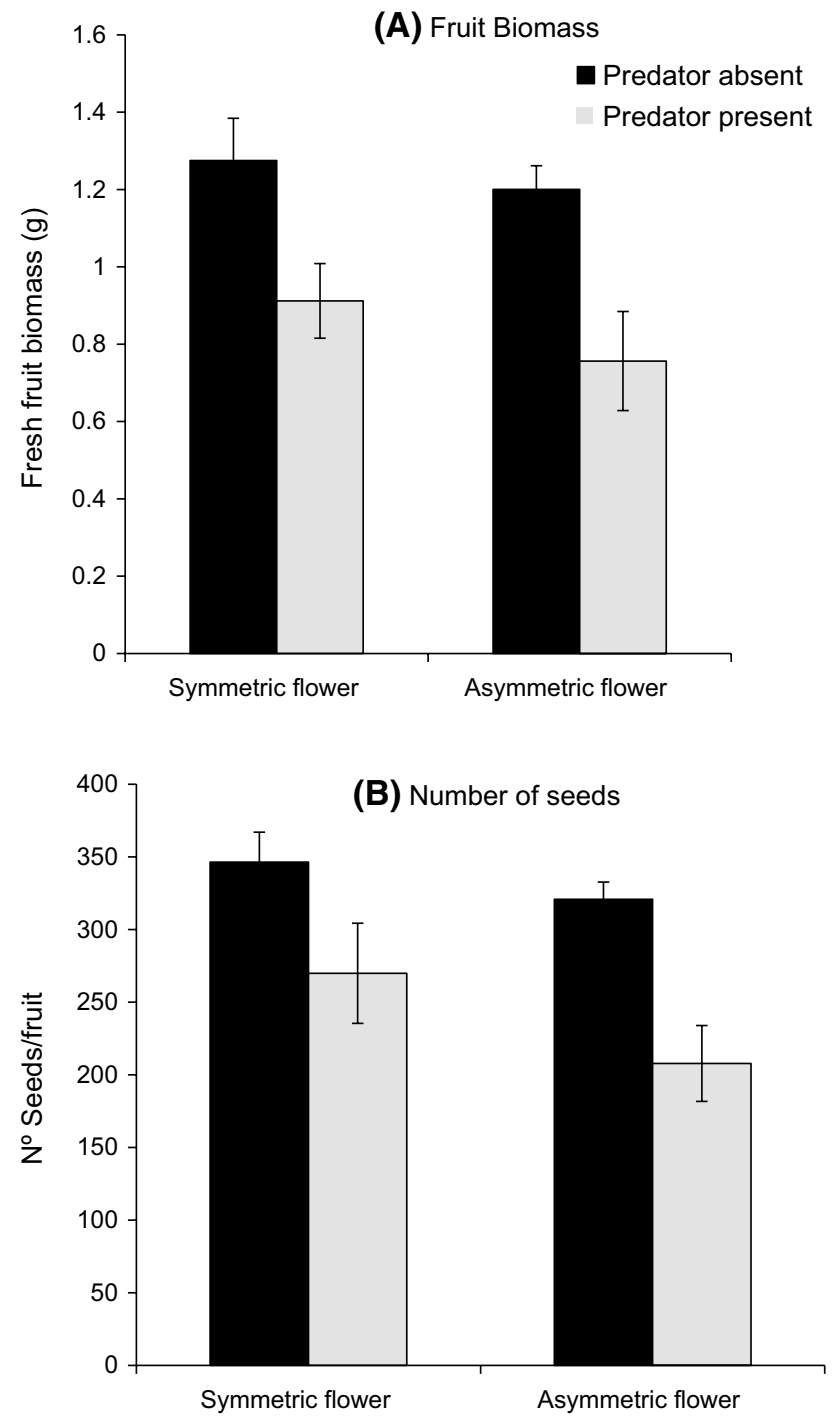

Fig. 2 a Mean biomass of fresh fruits $(\mathrm{g})$ and $\mathbf{b}$ number of seeds from symmetric and asymmetric flowers (flowers with two neighboring petals removed) in the presence and absence of predators (artificial crab spider). Error bars represent $\pm \mathrm{SE}$

\section{Discussion}

We have demonstrated that predator presence and floral asymmetry affected the total visits by insects and Hymenoptera and that avoidance behavior of flower-visiting insects was positively affected by predator presence, which in turn caused a cascade effect on the plant, decreasing its fitness components. In addition, insect visiting and avoidance behavior responded differently to florivory and predation risk effects and affected the fitness of $R$. rosifolius differently. Overall, interactive effects of predation risk and floral asymmetry were not relevant for this system, thus characterizing the additive effects of these factors on insect behaviors and plant fitness.
The lower number of insect visits in asymmetric flowers suggests the strong influence of florivores on the relationship between pollinators and plants (Sõber et al. 2010). As predicted, our results showed a clear preference of flowervisiting insects for symmetric flowers. This result is consistent with other studies in which Hymenoptera, the most abundant visitors in our study, showed a strong preference for symmetric flowers (Møller 1995; Wignall et al. 2006; McCall 2008). Symmetry can be an indicator of floral quality (Krupnick et al. 1999; Mothershead and Marquis 2000), suggesting larger amounts of available resources relative to flowers that do not have or have lost their petals in part or completely. Indeed, bees are able to detect symmetry patterns and generalize them for different symmetric flowers (Giurfa et al. 1996, 1999). Florivory simulated in $R$. rosifolius caused a bilateral symmetry pattern, which has been shown to inspire fewer visits by bees than the usual radial pattern (Wignall et al. 2006). However, asymmetry only affects flower recognition by flower-visiting insects, and it only decreases visitation behavior and not avoidance behavior. Therefore, florivory appears to be well recognized by flower-visiting insects and does not cause avoidance, a more complex behavior that demands higher energetic costs (Card et al. 2012). Understanding the relationship between florivory and its effect on pollinators is extremely important for understanding the evolution of flowering plants because floral characteristic evolution is deeply related to selection by pollinators as well as nonpollinator agents (e.g., floral herbivores) (Galen 1999; Strauss and Whittall 2006; McCall and Irwin 2006).

In contrast with the response to asymmetric flowers, pollinator insects responded to predation risk by visual recognition and avoidance behavior (i.e., visitation and avoidance, respectively). Our results confirm the predicted pattern, and pattern found in other studies in which the ability of pollinator insects to recognize morphologic attributes of predators was demonstrated (revised in Romero et al. 2011). Visual recognition patterns in relation to predator presence were common to all studied taxonomic groups, showing that Hymenoptera as well as Diptera and Lepidoptera can recognize and avoid places with predation risk (Weiss 2004; Sendoya et al. 2009; Yokoi and Fujisaki 2009; Brechbühl et al. 2010).

Predator attributes had a stronger effect on the avoidance behavior of pollinators compared with that of floral asymmetry, which was likely caused by the strong pressure exerted by predation per se and increased survival observed in insects with the ability to detect and avoid these risks because of the reduced likelihood of capture (Ings and Chittka 2009; Abbott and Dukas 2009). In addition, although floral damage (i.e., asymmetric flowers) may alter the quality of the consumed resource (Krupnick et al. 1999), it does not exert the same degree of evolutionary 
Table 1 Coefficients for the fixed predictors of the different pollinator groups and behaviors included in the most parsimonious models [with $\Delta$ corrected Akaike information criterion $(A I C c)<2$ ] and for the averaged models that considered block as a random effect

\begin{tabular}{|c|c|c|c|c|c|c|c|c|c|c|c|c|}
\hline Model & PR & ASYM & PR:ASYM & FOL & FLR & DIAM & FT & $d f$ & $\mathrm{AICc}$ & $\Delta \mathrm{AICc}$ & $w$ & $R^{2}$ \\
\hline \multicolumn{13}{|c|}{ Total visitation } \\
\hline 1 & -9.02 & -9.87 & 6.25 & 0.09 & & 10.83 & -4.52 & 8 & $539.03^{\mathrm{a}}$ & $0.00^{\mathrm{a}}$ & $0.21^{\mathrm{a}}$ & $0.71^{\mathrm{a}}$ \\
\hline 2 & -9.15 & -9.76 & 6.65 & & & & -4.31 & 7 & 539.10 & 0.14 & 0.20 & 0.69 \\
\hline 3 & -5.89 & -6.75 & & & & 22.39 & -4.80 & 7 & 539.64 & 0.61 & 0.15 & 0.69 \\
\hline 4 & -5.82 & -6.43 & & & & & -4.36 & 6 & 540.10 & 1.06 & 0.12 & 0.67 \\
\hline 5 & -9.04 & -9.94 & 6.17 & 0.06 & & 19.25 & -4.62 & 8 & 540.44 & 1.40 & 0.10 & 0.72 \\
\hline Average & $-8.06^{\mathrm{a}}(1)$ & $-8.81^{\mathrm{a}}(1)$ & $6.42(0.68)$ & $0.07(0.22)$ & & $21.11(0.51)$ & $-4.52^{\mathrm{a}}(1)$ & 9 & & & & \\
\hline \multicolumn{13}{|c|}{ Hymenoptera visitation } \\
\hline 1 & -3.86 & -5.80 & & & & & -3.42 & 6 & $538.01^{\mathrm{a}}$ & $0.00^{\mathrm{a}}$ & $0.22^{\mathrm{a}}$ & 0.66 \\
\hline 2 & -6.36 & -8.30 & 4.97 & & & & -3.38 & 7 & 538.50 & 0.50 & 0.17 & 0.67 \\
\hline 3 & -3.92 & -6.07 & & & & 18.12 & -3.77 & 7 & 538.52 & 0.51 & 0.17 & 0.67 \\
\hline 4 & -6.26 & -8.39 & 4.66 & & & 17.01 & -3.71 & 8 & 539.29 & 1.28 & 0.11 & 0.68 \\
\hline 5 & -3.93 & -5.95 & & 0.06 & & & -3.33 & 7 & 539.49 & 1.49 & 0.10 & 0.67 \\
\hline Average & $-4.78^{\mathrm{a}}(1)$ & $-6.71^{\mathrm{a}}(0.90)$ & $4.84(0.33)$ & $0.07(0.12)$ & & $17.67(0.33)$ & $-3.55^{\mathrm{a}}(1)$ & 5 & - & - & - & - \\
\hline \multicolumn{13}{|c|}{ Lepidoptera+Diptera visitation } \\
\hline 1 & -0.63 & & & & & & -0.37 & 6 & $30.00^{\mathrm{a}}$ & $0.00^{\mathrm{a}}$ & $0.25^{\mathrm{a}}$ & 0.55 \\
\hline 2 & -0.56 & & & & -0.19 & & -0.37 & 5 & 30.84 & 0.83 & 0.16 & 0.57 \\
\hline 3 & -0.65 & & & & & 1.52 & -0.39 & 6 & 31.29 & 1.28 & 0.13 & 0.54 \\
\hline 4 & -0.64 & -0.19 & & & & & -0.35 & 7 & 31.37 & 1.36 & 0.12 & 0.56 \\
\hline 5 & -0.90 & -0.45 & 0.52 & & & & -0.33 & 7 & 31.73 & 1.73 & 0.10 & 0.58 \\
\hline Average & $-0.61^{\mathrm{a}}(1)$ & $-0.16(0.18)$ & $0.52(0.05)$ & $-0.01(0.14)$ & $-0.13(0.35)$ & $1.04(0.18)$ & $-0.34^{\mathrm{a}}(1)$ & 7 & - & - & - & - \\
\hline \multicolumn{13}{|c|}{ Total avoidance } \\
\hline 1 & 1.51 & & & & & 3.81 & & 5 & 229.61 & 0 & 0.34 & 0.70 \\
\hline 2 & 1.44 & & & & 0.25 & 3.85 & & 6 & 229.90 & 0.29 & 0.30 & 0.70 \\
\hline 3 & 1.50 & & & 0.01 & & 3.54 & & 6 & 230.38 & 0.77 & 0.23 & 0.71 \\
\hline 4 & 1.45 & & & 0.01 & 0.19 & 3.64 & & 7 & 231.60 & 1.99 & 0.13 & 0.70 \\
\hline Average & $1.48^{\mathrm{a}}(1)$ & & & $0.01(0.36)$ & $0.23(0.42)$ & $3.74^{\mathrm{a}}(1)$ & & - & - & - & - & - \\
\hline \multicolumn{13}{|c|}{ Hymenoptera avoidance } \\
\hline 1 & 1.48 & & & & & 3.85 & & 5 & 226.24 & 0 & 0.40 & 0.71 \\
\hline 2 & 1.42 & & & & 0.22 & 3.83 & & 6 & 226.81 & 0.57 & 0.30 & 0.71 \\
\hline 3 & 1.48 & & & 0.01 & & 3.56 & & 6 & 226.88 & 0.63 & 0.29 & 0.72 \\
\hline Average & $1.46^{\mathrm{a}}(1)$ & & & $0.01(0.29)$ & $0.22(0.30)$ & $3.75^{\mathrm{a}}(1)$ & - & - & - & - & - & - \\
\hline \multicolumn{13}{|c|}{ Lepidoptera+Diptera avoidance } \\
\hline 1 & 0.37 & & & & & 1.11 & & 8 & 167.48 & 0 & 0.36 & 0.48 \\
\hline 2 & 0.38 & & & & & & & 7 & 167.48 & 0 & 0.36 & 0.51 \\
\hline 3 & 0.34 & & & & 0.11 & & & 8 & 169.26 & 1.78 & 0.15 & 0.50 \\
\hline 4 & 0.32 & & & & 0.12 & 1.11 & & 9 & 169.42 & 1.94 & 0.14 & 0.47 \\
\hline Average & $0.41^{\mathrm{a}}(1)$ & & & & $0.10(0.28)$ & $1.97(0.49)$ & - & - & - & - & - & - \\
\hline
\end{tabular}

$d f$, AICc, $\triangle \mathrm{AICc}$ and Akaike weights ( $w$ ) derived from the AICc (AICc-w) are given for each model. Response variables: (1) visits, and (2) avoidance behavior (total, Hymenoptera and Diptera+Lepidoptera). Values in parentheses correspond to the contribution (i.e., importance) of each variable calculated over the best set of models. The proportion of the total variation in the response variables $\left(R^{2}\right)$ explained by the model is indicated

$P R$ Predation risk, ASYM asymmetry, FLR no. of flowers/plant, FOL no. of leaves/plant, DIAM floral diameter, FT flowering time (days)

a Most important predictor variables

pressure as that of predator-prey interactions. Cognitively, behavioral responses of flower-visiting insects demand complex mechanisms, both in visual capacity (Srinivasan and Zhang 2004) to recognize predation signals and motor responses to perform avoidance behavior before contact with potential danger (Card and Dickinson 2008; Boeing 
Table 2 Coefficients for the fixed predictors of plant component fitness included in the most parsimonious models (with $\triangle \mathrm{AICc}<2$ ) and for the averaged models that considered block as a random effect

\begin{tabular}{|c|c|c|c|c|c|c|c|c|c|}
\hline Model & $\mathrm{PR}$ & ASYM & PR:ASYM & DIAM & $d f$ & $\mathrm{AICc}$ & $\triangle \mathrm{AICc}$ & W & $R^{2}$ \\
\hline \multicolumn{10}{|c|}{ Fruit biomass } \\
\hline 1 & -0.41 & & & & 4 & 38.66 & 0 & 0.48 & 0.53 \\
\hline 2 & -0.40 & -0.11 & & & 5 & 39.50 & 0.84 & 0.31 & 0.55 \\
\hline 3 & -0.40 & & & 0.55 & 5 & 40.28 & 1.62 & 0.21 & 0.57 \\
\hline Average & $-0.41^{\mathrm{a}}(1)$ & $-0.11(0.31)$ & & $0.55(0.21)$ & - & - & - & - & - \\
\hline \multicolumn{10}{|c|}{ Number of seeds } \\
\hline 1 & -94.83 & -43.83 & & & 5 & 570.72 & 0 & 0.42 & 0.36 \\
\hline 2 & -94.83 & & & & 4 & 571.66 & 0.94 & 0.26 & 0.28 \\
\hline 3 & -93.85 & -46.01 & & 130.86 & 6 & 572.51 & 1.79 & 0.17 & 0.43 \\
\hline 4 & -76.58 & -25.58 & -36.50 & & 6 & 572.71 & 1.99 & 0.15 & 0.37 \\
\hline Average & $-91.85^{\mathrm{a}}(1)$ & $-40.54(0.74)$ & $-36.50(0.15)$ & $130.86(0.17)$ & - & - & - & - & - \\
\hline
\end{tabular}

$d f$, AICc, $\triangle \mathrm{AICc}$ and $w$ derived from the AICc (AICc- $w$ ) are given for each model. Values in parentheses correspond to the contribution (i.e., importance) of each variable calculated over the best set of models. The proportion of the total variation in the response variables $\left(R^{2}\right)$ explained by the model is indicated. For abbreviations, see Table 1

a Most important predictor variables
Fig. 3 Path analysis model of the effect of floral damage (i.e., asymmetry) and predation risk on pollinator behaviors (i.e., visitation and avoidance) and plant fitness components, $\mathbf{a}$ fruit biomass and $\mathbf{b}$ number of seeds. Arrow thickness is scaled to illustrate the relative strength of effects. ${ }^{*} P<0.05$, $* * * P<0.001 ; n s$ not significant

\section{(A)}

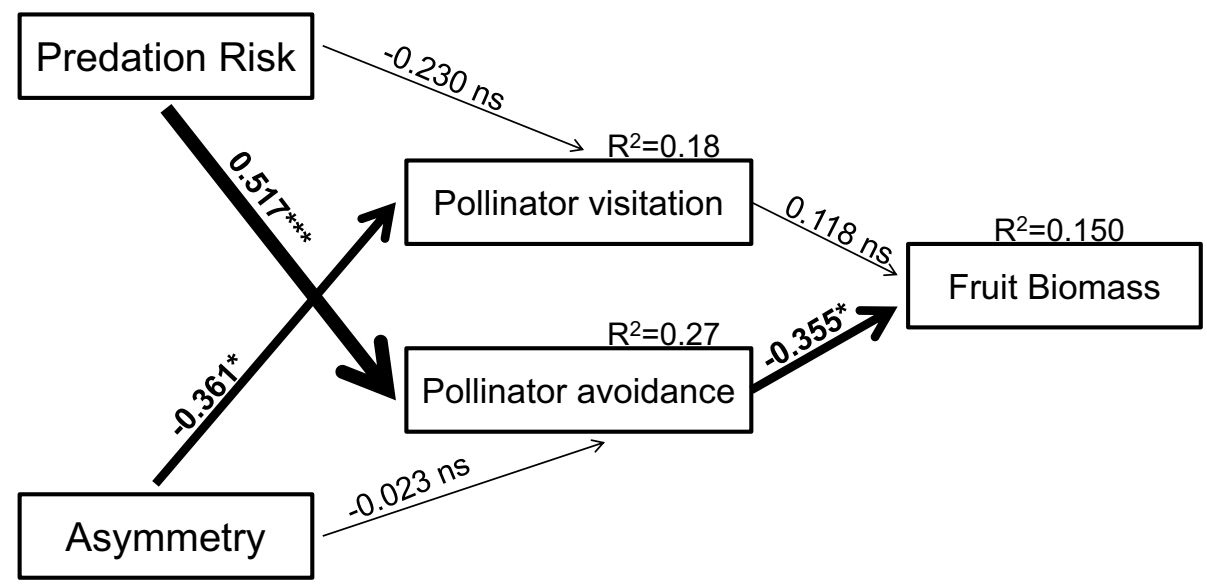

(B)

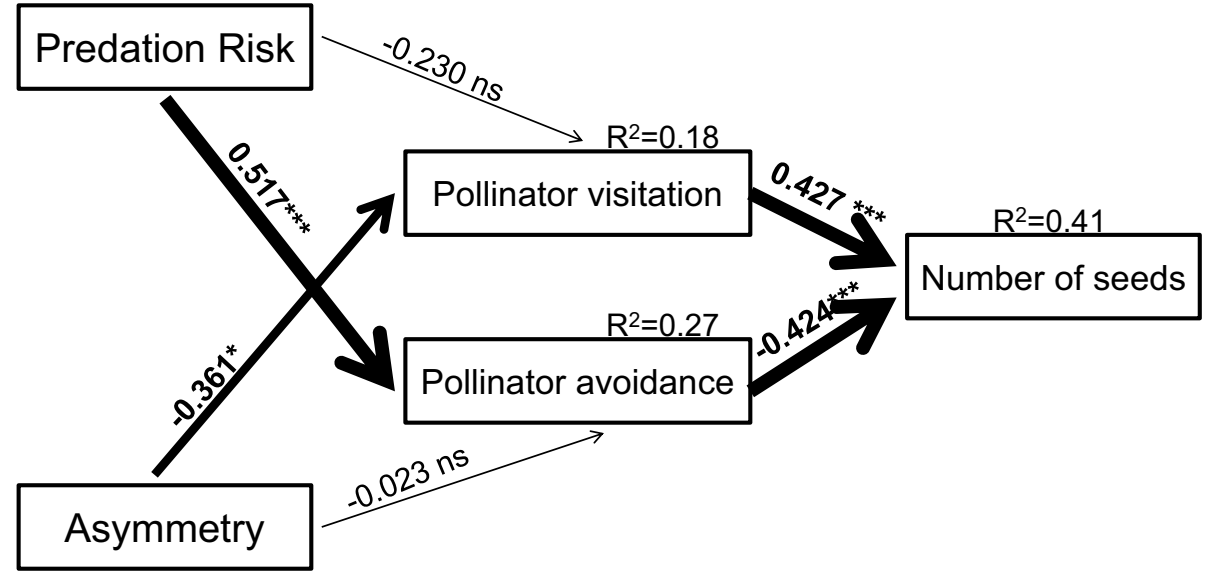


Table 3 Explanatory variables evaluating direct and indirect effects on variation in pollinator visitation and avoidance behavior, fruit biomass and number of seeds according to the causal models presented in Fig. 3

\begin{tabular}{lllll}
\hline Response variable & Explanatory variable & Coefficients & & \\
\cline { 3 - 5 } & & Direct effect $(d)$ & Indirect effect $(i)$ & Total effect $(e=d+i)$ \\
\hline \multirow{2}{*}{ Visit } & Asymmetry & -0.361 & - & -0.361 \\
& Predation risk & -0.230 & - & -0.23 \\
& Visitation & - & - & - \\
\multirow{5}{*}{ Avoidance } & Avoidance & - & - & - \\
& Asymmetry & 0.023 & - & 0.023 \\
& Predation risk & 0.517 & - & 0.517 \\
\multirow{5}{*}{ Fruit biomass } & Visitation & - & - & - \\
& Avoidance & - & - & - \\
& Asymmetry & - & -0.051 & -0.051 \\
& Predation risk & - & -0.210 & -0.210 \\
& Visitation & 0.118 & - & 0.118 \\
\cline { 2 - 4 } Number of seeds & Avoidance & -0.355 & - & -0.355 \\
& Asymmetry & - & -0.164 & -0.164 \\
& Predation risk & - & -0.317 & -0.317 \\
& Visitation & 0.427 & - & 0.427 \\
& Avoidance & -0.424 & - & -0.424 \\
\hline
\end{tabular}

2010; Dewell and Gabbiani 2012). Insect avoidance behavior demands a series of events between the neural stimulus and behavioral responses (Card et al. 2012). Therefore, this behavior is expected to occur in highly dangerous situations with signs of potential predators.

Overall, effects of risk of predation and of floral asymmetry did not interact, thus representing an additive accumulation of impacts associated with a single factor, i.e., flower-visiting insects visited asymmetric flowers less frequently in the presence of predators. Thus, pollinator insects were able to recognize predator signals and asymmetry. We demonstrated that herbivores and predators modify pollinator behavior and that this modification is stronger when they occur simultaneously. In certain circumstances, flower-visiting insects have limited attention; therefore, they are not able to recognize more than one stimulus at the same time (Wang et al. 2013). In our study system, pollinators efficiently distinguished between asymmetry and predation risk when the stimuli were presented together. One possible explanation is that in $R$. rosifolius, crab spiders, especially Misumenops argenteus and Misumenops callinurus (P. A. P. Antiqueira, personal observation), present similar behavior in symmetric and asymmetric flowers. Therefore, the pressure for obtaining resources and avoiding predation have increased the ability of flower-visiting insects to recognize symmetric patterns of flowers (Girufa et al. 1996, 1999) as indicators of resources and predator morphologic attributes even when they occur simultaneously. Understanding the combined effects of predators and herbivores on other organisms of different levels of the system is extremely important because both are common in nature and occur together in many natural systems (Ohgushi et al. 2007). In addition, multi-trophic interactions mediated by plants can have even greater complexity if the combined effects of the system's coexisting organisms is considered.

Our results showed that predation risk has caused a more intense effect on plant fitness compared with the effect of floral symmetry. Moreover, a path analysis showed that the behavior of pollinators distinctly affects plant reproductive success. Whereas infructescence biomass decreased with increased avoidance, the seed number increased with more visitations and decreased with higher avoidance from pollinators. Therefore, reduced fitness of $R$. rosifolius was indirectly affected by the risk of predation by crab spiders and primarily mediated by pollinator avoidance behavior. This result shows the importance of evaluating flower-vising insect behavior in terms of visitation and avoidance in studies involving plant fitness. In our study, predator effects are assumed to be mediated by pollinator behavior and considered non-lethal (Gonçalves-Souza et al. 2008) because we used artificial models. Our results highlight the importance of indirect effects mediated by predator attributes [traitmediated indirect interactions (Werner and Peacor 2003; Preisser et al. 2005)], which can have a greater effect compared with that of herbivores in animal-plant interactions.

In conclusion, floral asymmetry and potential predation risk in flowers had a cumulative effect on pollinator behavior. However, the magnitude of the effect of predation risk was stronger than that of floral asymmetry and considered a priority by insects during the visual recognition and avoidance process. Consequently, the indirect effects 
of predation risk reached the plant via non-consumptive indirect effects (i.e., trait-mediated indirect effects). To our knowledge, this is the first study to evaluate the combined effects of predation risk and floral damage (i.e., floral asymmetry) on flower-visiting behavior and plant fitness components. We suggest that further studies should be conducted to assess the combined mechanisms that affect the components of mutualism between pollinators and plants because in tropical ecosystems, both the presence of predators on flowers and effect of floral herbivores are ubiquitous. In addition, several interactions occur simultaneously in nature; therefore, approaches that consider the combined effects of predation and herbivory are more realistic. These approaches should be prioritized to develop a broader understanding of the ecological processes involved in pollinator-plant systems and consumer-resource interactions as a whole.

Acknowledgments We would like to thank Yuri Campanholo Gradinete and Prof. Dr André Victor Lucci Freitas for providing identifications of Hymenoptera and Lepidoptera, respectively; Dr Jennifer Thaler and an anonymous reviewer for their comments; Adriano Mendonça for providing help during fieldwork; and Prof. Dr Fernando Rodrigues da Silva for providing help with statistical analyses. We would also like to thank the City Hall of Jundiaí and staff of the Biological Reserve of Serra do Japi, Jundiaí. P. A. P. Antiqueira received a master's degree scholarship from the Fundação de Amparo à Pesquisa do Estado de São Paulo(FAPESP; proc. no. 2009/11874-6). G. Q. Romero received a productivity grant from the Brazilian National Council for Scientific and Technological Development (Conselho Nacional de Desenvolvimento Científico e Tecnológico). The present study was funded by FAPESP.

Author contribution statement $\quad$ P. A. P. A. and G. Q. R. conceived and designed the experiments, analyzed the data, and wrote the manuscript.

\section{References}

Abbott KR, Dukas R (2009) Honeybees consider flower danger in their waggle dance. Anim Behav 78:633-635

Althoff DM, Segraves KA, Pellmyr O (2005) Community context of an obligate mutualism: pollinator and florivore effects on Yucca wlamentosa. Ecology 86:905-913

Antiqueira PAP (2012) Efeitos indiretos de predadores e de herbívoros florais e foliares no comportamento de visitantes florais e sucesso reprodutivo de Rubus rosifolius. 96 f. Dissertação (mestrado), Universidade Estadual Paulista, Instituto de Biociências, Letras e Ciências Exatas. http://hdl.handle.net/11449/87627

Ashman TL, Knight TM, Steets JA, Amarasekare P et al (2004) Pollen limitation of plant reproduction: ecological and evolutionary causes and consequences. Ecology 85(9):2408-2421

Barton K (2015) MuMIn: multi-model inference. R package version 1.15.1. http://CRAN.R-project.org/package=MuMIn

Boeing WJ (2010) Defensive avoidance. In: Breed MD, Moore J (eds) Encyclopedia of animal behavior, vol 1. Academic Press, Oxford, pp 476-480

Botto-Mahan C, Ramírez PA, Ossa CG, Medel R, Ojeda-Camacho M, González AV (2011) Floral herbivory affects female reproductive success and pollinator visitation in the perennial herb Alstroemerialigtu (Alstroemeriaceae). Int J Plant Sci 172(9):1130-1136

Brechbühl R, Casas J, Bacher S (2010) Ineffective crypsis in a crab spider: a prey community perspective. Proc R Soc B 277:739-746

Burnham KP, Anderson DR (2002) Model selection and multimodel inference: a practical information-theoretic approach, 2nd ed. Springer, New York

Card GM (2012) Escape behaviors in insects. Curr Opin Neurobiol 22:180-186

Card G, Dickinson MH (2008) Visually mediated motor planning in the escape response of Drosophila. Curr Biol 18:1300-1307

Cardel YJ, Koptur S (2010) Effects of florivory on the pollination of flowers: an experimental field study with a perennial plant. Int $\mathbf{J}$ Plant Sci 171:283-292

CariveauD, Irwin RE, Brody AK, Garcia-Mayeya LS, Von der Ohe A (2004) Direct and indirect effects of pollinators and seed predators to selection on plant and floral traits. Oikos 104:15-26

Dewell RB, Gabbiani F (2012) Escape behavior: linking neural computation to action. Curr Biol 22(5):R152

Dukas R, Morse DH (2003) Crab spiders affect flower visitation by bees. Oikos 101:157-163

Dukas R, Morse DH (2005) Crab spiders show mixed effects on flower-visiting bees and no effect on plant fitness components. Ecoscience 12:244-247

Foelix RF (2010) Biology of spiders, 3rd edn. Oxford University Press, USA

Galen C (1999) Why do flowers vary? Bioscience 49(8):631-640

Giurfa M, Dafni A, Neal PR (1999) Floral symmetry and its role in plant-pollinator systems. Int J Plant Sci 160(6 Suppl):S41-S50

GiurfaM, Eichmann B, Menzel B (1996) Symmetry perception in an insect. Nature 382:458-461

Gonçalves-Souza T, Omena PM, Souza JC, Romero GQ (2008) Trait mediated effects on flowers: artificial spiders deceive pollinators and decrease plant fitness. Ecology 89:2407-2413

Ings TC, Chittka L (2009) Predator crypsis enhances behaviourally mediated indirect effects on plants by altering bumblebee foraging preferences. Proc R Soc Lond B 276:2031-2036

Ings TC, Montoya JM, Bascompte J, Blüthgen $\mathrm{N}$, Brown $\mathrm{L}$ et al (2009) Ecological networks-beyond food webs. J Anim Ecol 78:253-269

Karban R, Baldwin IT (1997) Induced responses to herbivory. University of Chicago Press, USA

Karban R, Strauss SY (1993) Effects of insect herbivores on the growth and reproduction of their long-lived host plant, Erigeronglaucus. Ecology 74:39-46

Knight TM, Steets JA, Vamosi JC, Mazer SJ, Burd M et al (2005a) Pollen limitation of plant reproduction: pattern and process. Annu Rev Ecol Evol Syst 36:467-497

Knight TM, McCoy MW, Chase JM, McCoy KA, Holt RD (2005b) Trophic cascades across ecosystems. Nature 437:880-883

Krupnick GA, Weis AE, Campbell DR (1999) The consequences of floral herbivory for pollinator service to Isomerisarborea. Ecology 80:125-134

Kvalseth TO (1985) Cautionary note about $R^{2}$. Am Stat 39:279-285

Lloyd DG, Barrett SCH (2006) Floral biology: studies on floral evolution in animal-pollinatedplants. Chapman and Hall, New York

Louda SM (1983) Seed predation and seedling mortality in the recruitment of a shrub, Haplopappusvenetus (Asteraceae), along a climatic gradient. Ecology 64:511-521

Maron JL, Crone E (2006) Herbivory: effects on plant abundance, distribution and population growth. Proc R Soc Lond B Biol Sci 273:2575-2584

Marquis RJ (1984) Leaf herbivores decrease fitness of a tropical plant. Science 226:537-539 
McCall AC (2008) Florivory affects pollinator visitation and female fitness in Nemophilamenziesii. Oecologia 155:729-737

McCall AC, Irwin RE (2006) Florivory: the intersection of pollination and herbivory. Ecol Lett 9:1351-1365

Møller AP (1995) Bumblebee preference for symmetrical flowers. Proc Natl Acad Sci USA 92:2288-2292

Morse DH (2007) Predator upon a flower: life history and fitness in a crab spider. Harvard University Press, Cambridge

Mothershead K, Marquis RJ (2000) Fitness impacts of herbivory through indirect effects on plant-pollinator interactions in Oenotheramacrocarpa. Ecology 81:30-40

Ohgushi T (2005) Indirect interaction webs: herbivore-induced effects through trait change in plants. Annu Rev Ecol Evol Syst 36:81-105

Ohgushi T, Craig TP, Price PW (2007) Ecological communities: plant mediation in indirect interaction webs. Cambridge University Press, Cambridge

Patiño J, Guilhaumon F, Whittaker RJ, Triantis KA, Gradstein SR, Hedenäs L, González-Mancebo JM, Vanderpoorten A (2013) Accounting for data heterogeneity in patterns of biodiversity: an application of linear mixed effect models to the oceanic island biogeography of spore-producing plants. Ecography 36:904-913

Piggott JJ, Townsend CR, Matthaei CD (2015) Reconceptualizing synergism and antagonism among multiple stressors. Ecol Evol 5:1538-1547

Pinheiro JC and Bates DM (2000) Mixed-effects models in S and S-PLUS. Springer, New York

Pinheiro J, Bates D, DebRoy S, Sarkar D, R Core Team (2015) nlme: linear and nonlinear mixed effects models. $\mathrm{R}$ package version 3.1-122. http://CRAN.R-project.org/package $=$ nlme

Preisser EL, Bolnick DI, Benarda MF (2005) Scared to death? The effects of intimidation and consumption in predator-prey interactions. Ecology 86:501-509. doi:10.1890/04-0719

R Core Team (2015) R: a language and environment for statistical computing. R Foundation for Statistical Computing, Vienna. https://www.Rproject.org/

Robertson IC, Maguire DK (2005) Crab spiders deter insect visitations to slickspot peppergrass flowers. Oikos 109:577-582

Romero GQ, Koricheva J (2011) Contrasting cascade effects of carnivores on plant fitness: a meta-analysis. J Anim Ecol 80:696-704

Romero GQ, Vasconcellos-Neto J (2004) Beneficial effects of flowerdwelling predators on their host plant. Ecology 85:446-457

Romero GQ, Antiqueira PAP, Koricheva J (2011) A meta-analysis of predation risk effects on pollinator behaviour. PLoS One 6(6):e20689. doi:10.1371/journal.pone.0020689

Santoro E, Machado DL (1992) Elementos geológicos da Serra do Japi (Geological elements of Serra do Japi). In: Morelatto LPC (ed) História natural da Serra do Japi. UNICAMP, Campinas, pp 24-29
Santos AMC, Carneiro FM, Cianciaruso MV (2015) Predicting productivity in tropical reservoirs: the roles of phytoplankton taxonomic and functional diversity. Ecol Ind 48:428-435

Schiestl FP, Johnson SD (2013) Pollinator-mediated evolution of floral signals. Trends Ecol Evol 28(5)

Schmitz OJ (1998) Direct and indirect effects of predation and predation risk in old-field interaction webs. Am Nat 151:327-342

Sendoya SF, Freitas AVL, Oliveira PS (2009) Egg-laying butterflies distinguish predaceous ants by sight. Am Nat 174:34-140

Sõber V, Moora M, Teder T (2010) Florivores decrease pollinator visitation in a self-incompatible plant. Basic Appl Ecol 11:669-675

Srinivasan MV, Zhang S (2004) Visual motor computations in insects. Annu Rev Neurosci 27:679-696

Stocks R, McPeek MA, Mitchell JL (2003) Evolution of prey behaviour in response to changes in predatory regime: damselflies in fish and dragonfly lakes. Evolution 57:574-585

Strauss SY (1997) Floral characters link herbivores, pollinators, and plant fitness. Ecology 78(6):1640-1645

Strauss SY, Whittall JB (2006) Non-pollinator agents of selection on floral traits. In: Harder LD, Barret SCH (eds) Ecology and evolution of flowers. Oxford University Press, Oxford

Suttle KB (2003) Pollinators as mediators of top-down effects on plants. Ecol Lett 6:688-694

Wang MY, Ings TC, Proulx MJ, Chittka L (2013) Can bees simultaneously engage in adaptive foraging behaviour and attend to cryptic predators? Anim Behav 86-859:866

Weiss MR (2004) Vision and learning in some neglected pollinators: beetles, flies, moths, and butterflies. In: Chittka L, Thomson JD (eds) Cognitive ecology of pollination: animal behaviour and floral evolution. Cambridge University Press, Cambridge, pp 171-190

Wignall AE, Helling AM, Cheng K, Herberstein ME (2006) Flower symmetry preferences in honeybees and their crab spider predators. Ethology 112:510-518

Wise MJ, Cummins JJ (2002) Nonfruiting hermaphroditic flowers as reserve ovaries in Solanumcarolinense. Am Midl Nat J 148:236-245

Wootton JT (1994) The nature and consequences of indirect effects in ecological communities. Annu Rev Ecol Syst 25:443-466

Yokoi T, Fujisaki K (2009) Hesitation behaviour of hoverflies Sphaerophoria spp. to avoid ambush by crab spiders. Naturwissenschaften 96:195-200

Zuur AF, Ieno EN, Walker NJ, Saveliev AA, Smith GM (2009) Mixed effects models and extensions in ecology with R, 1st edn, XXII. Springer, New York 